\title{
Dissolution and Chain Dimensions of Nylon 6 in Metal Halide-Alcohol Systems
}

\author{
Akio NaKaJima* and Kazuo TANAAMI \\ Department of Polymer Chemistry, Kyoto University, \\ Sakyo-ku, Kyoto 606, Japan.
}

(Received March 5, 1973)

\begin{abstract}
The dissolution mechanism of Nylon 6 was investigated in connection with the chain conformations of the polymer in some complex solvents, such as the metal halide-alcohol systems. Infrared studies on both the polymer solutions and the metal halide-alcohol mixtures revealed that Nylon 6 forms a complex with the metal halidealcohol complex solvent. The characteristic ratio $\left(\left\langle R_{0}^{2}\right\rangle / n \bar{l}^{2}=9.41\right)$ of Nylon 6 was determined in a $15-\mathrm{g} \mathrm{CaCl} \mathrm{Ca}_{2} / 100-\mathrm{m} l \mathrm{CH}_{3} \mathrm{OH}$ mixture at $35^{\circ} \mathrm{C}$, a theta solution, and is considerably larger than Flory's value, 6.08, in which the specific solvent effects were not taken into account. It is pointed out how the solvent interactions affect the shortrange interferences in the chain conformations in the complex solvent used in this work.
\end{abstract}

\section{KEY WORDS Nylon 6/ Metal Halide-Alcohol Complex / Solubility / IR Spectra / Characteristic Ratio / Unperturbed Chain Dimension /}

Though Nylon 66 is not soluble in alcohols at room temperature, it dissolves ${ }^{1}$ in mixtures such as alkali halide-alcohol, alkaline earth metal-alcohol, and rhodanate-alcohol; in particular, this polymer easily dissolves in alcohol containing lithium chloride, calcium chloride, or zinc chloride. However, little has been reported on the dissolution mechanism of Nylon in these solvent systems or on the properties of these solutions.

Ford and Marshall ${ }^{2}$ have performed analyses of the infrared and ultraviolet spectra of Nylon 66 in the $\mathrm{LiCl}-$ methanol, $\mathrm{TiCl}_{4}-$ methanol, and $\mathrm{SnCl}_{4}$-amyl alcohol systems, and have pointed out that a coordination complex is formed between the metallic halide and the alcohol, with a coordinate bond between this complex and the amide oxygen atom of Nylon 66 .

Aoki $^{3}$ investigated the dissolution of Nylon 6 in $\mathrm{CaCl}_{2}-$ methanol, and pointed out that when one of the methanol molecules coordinated to a $\mathrm{Ca}^{++}$is removed, simultaneously the unpaired electron of the $\mathrm{O}$ atom in the amide group of Nylon 6 coordinates to the $\mathrm{Ca}^{++}$. Thus, intermolecular hydrogen bonds, $>\mathrm{C}=\mathrm{O} \cdots \mathrm{H}-\mathrm{N}<$,

\footnotetext{
* To whom correspondence should be addressed.
}

between the amide groups of Nylon 6 are destroyed and Nylon 6 dissolves in the solvent (see Figure 1). When water is added to such a Nylon solution (II), water molecules may be replaced by the $\mathrm{CH}_{3} \mathrm{OH}$, molecules coordinated to $\mathrm{Ca}^{++}$because of the considerable electronegativity of the water molecules. At the same time, the coordinate bond force between the $O$ atom of the Nylon and the Ca-complex is diminished. Thus the insolubility of the polymer in alcohol is due to the formation of intermolecular hydrogen bounds.

For the chain conformations of Nylon, Saunders ${ }^{4}$ investigated the relation between the

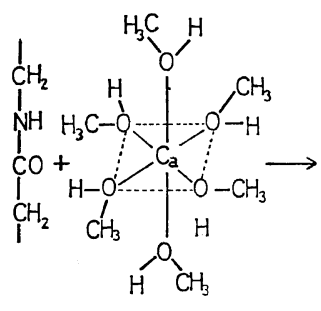

(I)

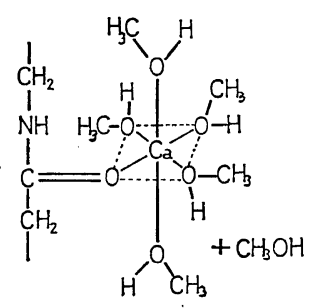

(II)
Figure 1. Dissolution mechanism of Nylon 6 in $\mathrm{CaCl}_{2}$-methanol system, as proposed by Aoki. ${ }^{3}$ 
unperturbed mean-square end-to-end distance $\left\langle R_{0}^{2}\right\rangle$ of the chain and the molecular weight $M$, using the viscosity data of Nylon 66 in a 90-\% formic acid aqueous solution containing 2.3-mol/l $\mathrm{KCl}$. $\mathrm{He}$ obtained a result of $\left[\left\langle R_{0}^{2}\right\rangle / M\right]^{1 / 2}=96 \times 10^{-10} \mathrm{~cm} \mathrm{~mol}^{1 / 2} \mathrm{~g}^{-1 / 2}$. Kurata and Stockmayer ${ }^{5}$ also reported $\left[\left\langle R_{0}^{2}\right\rangle / M\right]^{1 / 2}=$ $89 \times 10^{-10}$ for Nylon 66 from viscosity data in $m$-cresol. On the other hand, Flory and Williams ${ }^{6}$ carried out theoretical calculations on $\left\langle R_{0}^{2}\right\rangle$ for Nylon 66 and Nylon 6 , and pointed out that the relation between $\left\langle R_{0}^{2}\right\rangle$ and $M$ obtained for both polymers is quite similar. We used the relationship between the molecular weight of Nylon 6 and the limiting viscocity number $[\eta]$ in a $90-\%$ formic acid aqueous solution or in $m$-cresol, as reported by Watanabe, ${ }^{7}$ to determine the molecular weight of the polymer.

The purpose of this work is to investigate the complex formation and polymer chain conformations in metal halide-alcohol systems: in particular, in $\mathrm{CaCl}_{2}$-methanol for Nylon 6 . The results will be compared with those for Nylon 66 reported by Ford ${ }^{2}$, and for Nylon 6 proposed by Aoki. ${ }^{3}$

\section{EXPERIMENTAL}

\section{Materials}

Nylon 6 samples with different molecular weights were supplied through the courtesy of the Unitica Co. According to the purposes of the experiment these samples were fractionated. When fractionation was not necessary, the samples were purified twice in a formic acidmethanol system before use. If necessary, fractionations were carried out in a phenolwater system at $70^{\circ} \mathrm{C}$. Alcohols and metal chlorides used were of Reagent Grade from Nakarai Chemical Co.

\section{Solubility}

A given amount of metal chloride was dissolved in alcohol under agitation in test tube at $30^{\circ} \mathrm{C}$. Solubility of Nylon 6 in the solvent thus prepared was estimated by the content of the polymer dissolved after an agitation of $24 \mathrm{hr}$ at $30^{\circ} \mathrm{C}$ while adding the polymer to the solvent.

\section{Infrared Spectra}

Infrared absorption spectra were measured with a Nihon Kogaku Model DS-402G spectrophotometer at $30^{\circ} \mathrm{C}$. Measurements were carried out using methanol solutions saturated with metal halide, and $10-\mathrm{g} / \mathrm{d} l$-Nylon 6 solutions in these methanol solutions saturated with metal halide. For each case, a rock salt plate was used. The methanol used was Merk's Infrared Reagent Grade. Metal chloride were used after dehydrating with a vacuum pump under heating.

\section{Viscosity Measurements}

An Ostwald-type or Ubbelohde-type viscometer was used separately according to the purpose to obtain the limiting viscosity number $[\eta]$ from viscosity measurements. A characteristic feature in viscosity measurements for Nylon solutions in metal halide-alcohol systems is that the viscosity of the solvent (i.e., metal halidealcohol mixture) is high. Such behavior is attributed to the fact that these complex solvents (I in Figure 1) form hydrogen bonds with each other or with the alcohol molecules. The viscosity of the solvent is reduced by increasing the amount of water added.

\section{RESULTS AND DISCUSSION}

\section{Solubility of Metal Chlorides in Alcohols}

Table I shows the experimental results for the solubility ( $\mathrm{g}$ metal halide in $\mathrm{d} l$ alcohol) of metal halides in several aliphatic alcohols at $30^{\circ} \mathrm{C}$.

Table I. Solubility of metal halides, anhydrides, and hydrides in aliphatic alcohols at $30^{\circ} \mathrm{C}$

\begin{tabular}{lcccc}
\hline & \multicolumn{4}{c}{ Solubility, g halide/d alcohol } \\
\cline { 2 - 5 } Metal halide & Methanol & Ethanol $\begin{array}{c}n \text { - } \\
\text { Butanol }\end{array}$ & $\begin{array}{c}i \text {-Propa- } \\
\text { nol }\end{array}$ \\
\hline $\mathrm{LiCl}$ & 40 & 20 & 10 & Very small \\
$\mathrm{CaCl}_{2}$ & 30 & 25 & 7 & Very small \\
$\mathrm{CaCl}_{2} \cdot \mathrm{H}_{2} \mathrm{O}$ & 50 & 40 & - & - \\
$\mathrm{CaCl}_{2} \cdot 2 \mathrm{H}_{2} \mathrm{O}$ & 75 & 65 & - & - \\
$\mathrm{CaCl}_{2} \cdot 4 \mathrm{H}_{2} \mathrm{O}$ & 100 & 90 & - & - \\
$\mathrm{CaCl}_{2} \cdot 6 \mathrm{H}_{2} \mathrm{O}$ & 150 & 125 & - & - \\
$\mathrm{ZnCl}_{2}$ & 120 & 100 & 20 & Very small \\
$\mathrm{MgCl}_{2} \cdot 6 \mathrm{H}_{2} \mathrm{O}$ & Very large Very.large & - & Very small \\
\hline
\end{tabular}

\section{Solubility of Nylon 6 in Metal Chloride-Alcohol Mixtures}

The solvent compositions in which 0.2-g Nylon 6 can be dissolved to form an alcohol-metal 
Table II. Composition range of metal chloridealcohol mixtures in which Nylon 6 can. be dissolved at $30^{\circ} \mathrm{C}$

\begin{tabular}{|c|c|c|c|}
\hline \multirow{2}{*}{ Metal halide } & \multicolumn{3}{|c|}{$\begin{array}{l}\text { Solvent composition } \\
\text { ( } \mathrm{g} \text { halide/d } l \text { alcohol) }\end{array}$} \\
\hline & Methanol & Ethanol & n-Butanol \\
\hline $\mathrm{LiCl}$ & $15-40$ & $10-20$ & Insoluble \\
\hline $\mathrm{CaCl}_{2}$ & $\begin{array}{c}7-30 \\
(50-12)^{\mathrm{a}}\end{array}$ & $\begin{array}{c}5-25 \\
(48-10)^{\mathrm{a}}\end{array}$ & Insoluble \\
\hline $\mathrm{CaCl}_{2} \cdot \mathrm{H}_{2} \mathrm{O}$ & $\begin{array}{l}10-50 \\
(40-8)^{\mathrm{a}}\end{array}$ & $\begin{array}{l}10-40 \\
(28-7)^{\mathrm{a}}\end{array}$ & Insoluble \\
\hline $\mathrm{CaCl}_{2} \cdot 2 \mathrm{H}_{2} \mathrm{O}$ & $\begin{array}{l}15-75 \\
(31-5)^{\mathrm{a}}\end{array}$ & $\begin{array}{l}10-65 \\
(32-5)^{\mathrm{a}}\end{array}$ & Insoluble \\
\hline $\mathrm{CaCl}_{2} \cdot 4 \mathrm{H}_{2} \mathrm{O}$ & $\begin{array}{l}30-100 \\
(19-6)^{\mathrm{a}}\end{array}$ & $\begin{array}{c}15-90 \\
(27-4)^{\mathrm{a}}\end{array}$ & Insoluble \\
\hline $\mathrm{CaCl}_{2} \cdot 6 \mathrm{H}_{2} \mathrm{O}$ & $\begin{array}{l}50-150 \\
(14-5)^{\mathrm{a}}\end{array}$ & $\begin{array}{l}50-125 \\
(10-4)^{\mathrm{a}}\end{array}$ & Insoluble \\
\hline $\mathrm{ZnCl}_{2}$ & $25-120$ & $20-100$ & Insoluble \\
\hline
\end{tabular}

a Numbers in parentheses denote the mol ratio of alcohol to $\mathrm{Ca}$ in the solvent systems in which Nylon 6 is dissolved.

chloride mixture at $30^{\circ} \mathrm{C}$ are shown in Table II.

As is obvious from Tables I and II, the upper concentration limit of the metal halide in alcohol corresponds to the saturation concentration for each system. Generally, the solubility of Nylon 6 is reduced with decreasing concentration of metal halide from its saturation concentration and ultimately becomes zero. The lower limit concentration denotes the solvent composition at which the solubility of Nylon 6 becomes zero. The effect of hydrated water is as follows: the solubility of Nylon 6 in mono- and dihydride is not so different from that in the anhydride, but is reduced considerably in the tetrahydride. In the hexahydride, the Nylon 6 swells but cannot be dissolved.

The decrease in solubility seems to be more noticable with methanol than with ethanol. The solubility of Nylon 6 is extremely low in butanol for each system. If we assume the coordination number of $\mathrm{Ca}$ to be 6 , as shown in Figure 1, the numbers (mol alcohol/mol $\mathrm{Ca}$ ) appearing in parentheses in Table II are quite reasonable.

We point out that a $\mathrm{CaCl}_{2}$-methanol or $\mathrm{CaCl}_{2}$-ethanol mixture containing a comparatively small amount of $\mathrm{CaCl}_{2}$ can dissolve Nylon 6 , and the addition of water reduces the solubility of Nylon 6. Aoki ${ }^{3}$ has reported that Nylon 6 is not soluble in a $\mathrm{MgCl}_{2}$-methanol mixture, but our result shows that methanol solutions saturated (at room temperature) with $\mathrm{MgCl}_{2}$ can dissolve more than $5 \mathrm{~g} / \mathrm{d} l$ of Nylon 6 at $40^{\circ} \mathrm{C}$.

Solubility of Nylon 6 in $\mathrm{HCl}$-Alcohol Mixtures

Additional investigation were performed with $\mathrm{HCl}$ in place of the metal chlorides. The alcohols used were methanol, ethanol, plus benzyl alcohol,' and ethylene glycol. These alcohols were saturated with $\mathrm{HCl}$ gas at $0^{\circ} \mathrm{C}$. The concentrations of $\mathrm{HCl}$ in methanol and ethanol were 1.9 and 3.0 mol\%, respectively.

Table III. Solubility of Nylon 6 in $\mathrm{HCl}$-alcohol saturation solutions at room temperature

\begin{tabular}{lc}
\hline $\mathrm{HCl}$-Alcohol & Solubility of Nylon 6 \\
\hline $\mathrm{HCl}$-Methanol & very large \\
$\mathrm{HCl}$-Ethanol & very large \\
$\mathrm{HCl}$-Benzyl alcohol & large \\
$\mathrm{HCl}$-Ethylene glycol & large \\
\hline
\end{tabular}

A methanol solution saturated with $\mathrm{HCl}$ $(1.9$ mol $\%$ ) dissolved more than $10 \mathrm{~g} / \mathrm{d} l$ of Nylon 6 at room temperature. Moreover, the precipitation temperature of this solution was observed to be slightly below room temperature.

Infrared Spectra of Metal Chloride-Methanol, and of Nylon 6 in Metal Chloride-Methanol Mixtures

The $\mathrm{OH}$ stretching frequency $\nu_{\mathrm{OH}}$ of the $\mathrm{OH}$ of methanol in the metal chloride-methanol mixtures (Table IV) decreases in the order of $\mathrm{Cs}>\mathrm{Li}>\mathrm{H}, \mathrm{Ba}>\mathrm{Sr}>\mathrm{Ca}>\mathrm{Mg}>\mathrm{Ti}$. The polarizability of an ion is proportional to $z / r^{2}$, in which $z$ and $r$ are the valency of the ion and the ion radius, respectively; it reflects the strength of the electrostatic field of the ion. In Table $V$ are the polarizabilities of metal ions, calculated by using Goldschmit's ${ }^{8}$ values for the ion radii.

As is obvious from Table $\mathrm{V}, z / r^{2}$ decreases in the order of $\mathrm{Ti}>\mathrm{Mg}>\mathrm{Ca}>\mathrm{Li}>\mathrm{Sr}>\mathrm{Ba}>\mathrm{Cs}$. This result is in accord with that obtained for $\nu_{\mathrm{OH}}$ except that the order of $\mathrm{Li}$ and $\mathrm{Sr}$ is inverted. $\Delta \nu_{\mathrm{OH}}$ in Table IV gives the shift of the $\mathrm{OH}$ stretching frequency of the alcohol due to complex formation with the metal halide 
Dissolution and Chain Dimensions of Nylon 6 in Metal Halide-Alcohol Systems

Table IV. Infrared absorption spectra of metal chloride-methanol mixtures and of Nylon 6 dissolved in these mixed solvents $\left(30^{\circ} \mathrm{C}\right)$

\begin{tabular}{|c|c|c|c|c|c|}
\hline \multirow{3}{*}{$\begin{array}{l}\text { Metal } \\
\text { halide }\end{array}$} & \multirow{2}{*}{\multicolumn{2}{|c|}{$\begin{array}{l}\text { Mixed solvent } \\
\text { OH stretching }\end{array}$}} & \multicolumn{3}{|c|}{ Nylon 6 in mixed solvent } \\
\hline & & & \multicolumn{2}{|c|}{$(\mathrm{C}=\mathrm{Om}$ - stretching $)$} & \multirow{2}{*}{$\begin{array}{l}\underbrace{\text { Amide }}_{\text {II }} \\
\nu, \mathrm{cm}^{-1}\end{array}$} \\
\hline & $\begin{array}{l}\mathrm{\nu OH}, \\
\mathrm{cm}^{-1}\end{array}$ & $\begin{array}{l}\Delta \nu_{\mathrm{OH}}, \\
\mathrm{cm}^{-1}\end{array}$ & $\begin{array}{l}\nu \mathrm{CO}, \\
\mathrm{cm}^{-1}\end{array}$ & $\begin{array}{l}\Delta \nu_{\mathrm{CO}}, \\
\mathrm{cm}^{-1}\end{array}$ & \\
\hline $\mathrm{TiCl}_{4}$ & $3200^{a}$ & $450^{\mathrm{a}}$ & $1607^{a}$ & $80^{\mathrm{a}}$ & \\
\hline $\mathrm{TiCl}_{4}$ & & & 1610 & 77 & 1555 \\
\hline $\mathrm{MgCl}_{2}$ & 3260 & 400 & 1635 & 52 & 1560 \\
\hline $\mathrm{CaCl}_{2}$ & 3290 & 360 & 1635 & 52 & 1565 \\
\hline $\mathrm{SrCl}_{2}$ & 3310 & 340 & 1635 & 52 & 1550 \\
\hline $\mathrm{BaCl}_{2}$ & 3320 & 330 & & & \\
\hline $\mathrm{HCl}$ & 3320 & 330 & 1655 & 32 & 1540 \\
\hline $\mathrm{LiCl}$ & $3325^{\mathrm{a}}$ & & & & \\
\hline $\mathrm{LiCl}$ & 3320 & 330 & 1655 & 32 & 1555 \\
\hline $\mathrm{CsCl}$ & 3330 & 320 & & & \\
\hline \multicolumn{4}{|c|}{$\mathrm{CaCl}_{2}-N$-Methyl acetamide 1640} & 47 & 1580 \\
\hline \multirow{2}{*}{\multicolumn{6}{|c|}{ 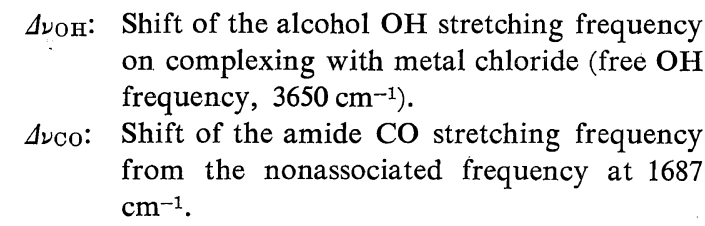 }} \\
\hline & & & & & \\
\hline \multicolumn{6}{|c|}{ Table V. Radius and polarizability of metal ions } \\
\hline \multicolumn{2}{|c|}{ Metal cation } & \multicolumn{3}{|c|}{ Ion radius, $(\AA)$} & $z / r^{2}$ \\
\hline \multicolumn{2}{|c|}{$\mathrm{Li}^{+}$} & \multicolumn{3}{|c|}{0.78} & 1.6 \\
\hline \multicolumn{2}{|c|}{$\mathrm{Cs}^{+}$} & \multicolumn{3}{|c|}{1.65} & 0.4 \\
\hline \multirow{2}{*}{\multicolumn{2}{|c|}{$\begin{array}{l}\mathrm{Mg}^{++} \\
\mathrm{Ca}^{++}\end{array}$}} & \multicolumn{3}{|c|}{0.78} & 3.3 \\
\hline & & \multicolumn{3}{|c|}{1.06} & 1.8 \\
\hline \multicolumn{2}{|c|}{$\mathrm{Sr}^{++}$} & \multicolumn{3}{|c|}{1.27} & 1.2 \\
\hline \multicolumn{2}{|c|}{$\mathrm{Ba}^{++}$} & & 1.43 & & 1.0 \\
\hline \multicolumn{2}{|c|}{$\mathrm{Ti}^{++}$} & \multicolumn{3}{|c|}{0.64} & 9.8 \\
\hline
\end{tabular}

relative to the frequency $3650 \mathrm{~cm}^{-1}$ for free $\mathrm{OH}$. Alternatively, the reference frequency may be taken as $3350 \mathrm{~cm}^{-1}$ by taking into account the shift $\left(300 \mathrm{~cm}^{-1}\right)$ due to the hydrogen bonding between methanol molecules. Thus, $\Delta \nu$ $\left(=\Delta \nu_{\mathrm{OH}}-300\right)$ was plotted against $z / r^{2}$ in Figure 2. $\Delta \nu$ increases with increasing strength of the electrostatic field of the ion. Such a result suggests that some of the methanol molecules contact directly with a metal ion at a distance corresponding to the ion radius.

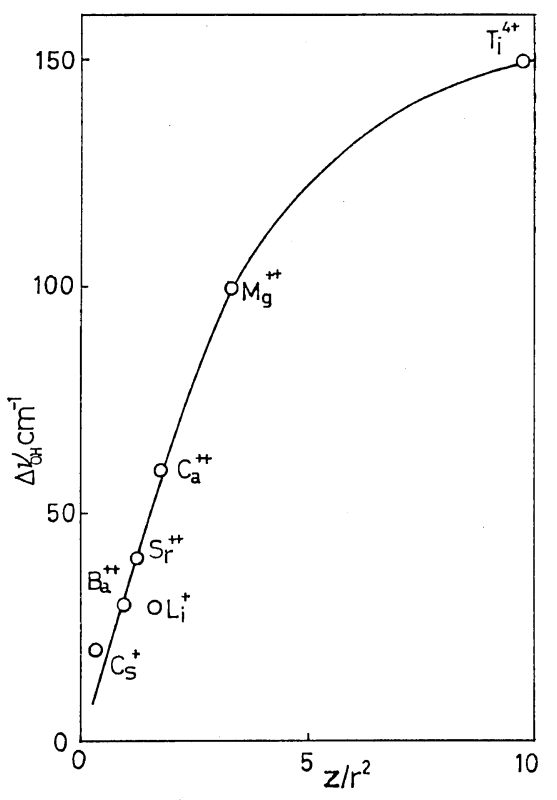

Figure 2. Shift $\Delta \nu$ of the OH-stretching frequency for metal cation-methanol systems, plotted against the polarizability of metal cations $\left(30^{\circ} \mathrm{C}\right)$.

$\nu_{\mathrm{CO}}, \Delta \nu_{\mathrm{CO}}$, and $\nu$ in Table IV concern Nylon 6 dissolved in methanol-metal chloride mixtures. The amide $I$ band is assigned to the $\mathrm{C}=\mathrm{O}$ stretching frequency of the amide group. In accordance with the valency of the coexisting metal cation, $\nu_{\text {CO }}$ takes three different values, i.e., $1655 \mathrm{~cm}^{-1}, \quad 1635 \mathrm{~cm}^{-1}$, and $1610 \mathrm{~cm}^{-1}$, respectively, for uni-, di-, and tetravalent cations. By assuming the $\mathrm{CO}$ stretching frequency of the nonassociated amide ${ }^{2}$ to be 1687 $\mathrm{cm}^{-1}$, the frequency shift from there was designated as $\Delta \nu_{\mathrm{CO}}$. The fact that the values of $\Delta \nu_{\mathrm{CO}}$ for three divalent cations, $\mathrm{Mg}, \mathrm{Ca}$, and $\mathrm{Sr}$, are identical, in spite of the difference in their ionic radii, suggests that the coordinate bond strength between the cation and the carbonyl oxygen atom is independent of the ionic radii of the divalent cations. The model (II) in Figure 1, in which the metal cation and the carbonyl oxygen atom are assumed to contact each other at the ion radius and the van der Waals radius, respectively, may not be the decisive one. For the distance between the metal cation and the carbonyl oxygen atom may be somewhat larger than the sum of the ion radius and van der Waals radius, because of 


\section{A. Nakajima and $\mathrm{K}$. TanaAmi}

interactions between the methylene group of Nylon and the methanol molecules coordinating to the metal cations. When this distance becomes sufficiently large, the effect of the ion radius of the metal cation may disappear. In the case of divalent cations, $\Delta \nu_{\mathrm{OH}}$ varies from $400 \mathrm{~cm}^{-1}$ for $\mathrm{Mg}$ to $330 \mathrm{~cm}^{-1}$ for $\mathrm{Ba}$, but $\Delta \nu_{\mathrm{CO}}$ does not vary for either cations and remains at $52 \mathrm{~cm}^{-1}$. The difference in the infrared absorption spectra between univalent and tetravalent cations may be understood from electrostatic interactions. The amide II band has been assigned $d^{9}$ to the coupling of $\delta(\mathrm{NH})$ with $\nu(\mathrm{C}-\mathrm{N})$, and is known to appear at $1560 \mathrm{~cm}^{-1}$ for Nylon 6 itself. Numerical values of $\nu$ listed in Table IV are approximately constant within $\pm 5 \mathrm{~cm}^{-1}$, except the one for the $\mathrm{H}^{+}$system. This result may mean that the conformation of this atomic group is not largely affected by the presence of a solvent. On the last line of Table IV, numerical values for $N$-methyl acetamide- $-\mathrm{CaCl}_{2}$ system are shown for comparison.

Later, we will refer further to the interaction of these complex solvents with Nylon 6, in relation to the chain dimensions of Nylon in these solvents.

Relation between [ $\eta]$ and $\mathrm{M}$ in $\mathrm{CaCl}_{2}-$ Methanol Systems

The molecular weight $M$ of Nylon 6 was estimated from [ $\eta]$ in $\mathrm{d} l / \mathrm{g}$ at $25^{\circ} \mathrm{C}$ by using eq 1 , which was obtained by rearranging the result reported by Watanabe. ${ }^{7}$

$$
\begin{aligned}
& {[\eta]=1.10 \times 10^{-3} M^{0.72},} \\
& \quad \text { in } 90-\% \text { formic acid aq solution }
\end{aligned}
$$

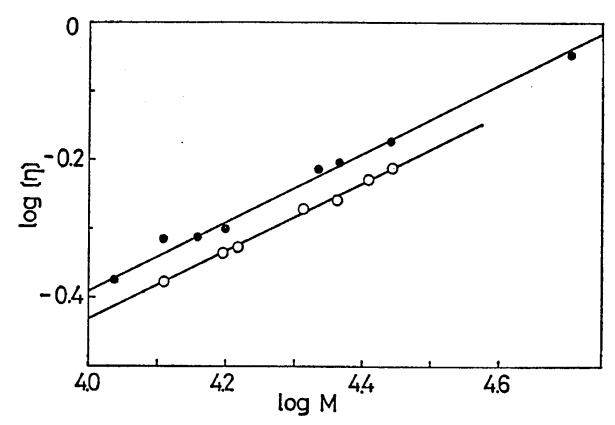

Figure 3. Relation between $M$ of Nylon 6 and $[\eta]$ in $\mathrm{CaCl}_{2}$-methanol systems at $35^{\circ} \mathrm{C}$. Solvent composition: (○) $15-\mathrm{g} \mathrm{CaCl}_{2} / \mathrm{d} l$ methanol; (○) $20-\mathrm{g}$ $\mathrm{CaCl}_{2} / \mathrm{d} l$ methanol.
Figure 3 shows the relations between the molecular weight $M$ and the $[\eta]$ at $35^{\circ} \mathrm{C}$ in $15-\mathrm{g}$ $\mathrm{CaCl}_{2} / \mathrm{d} l$ methanol and in $20-\mathrm{g} \mathrm{CaCl}_{2} / \mathrm{d} l$ methanol systems for fractionated Nylon 6 samples. Two straight lines in Figure 3 lead to the following equations:

$$
\begin{aligned}
{[\eta] } & =3.68 \times 10^{-3} M^{0.50}, \\
& \text { in } 15-\mathrm{g} \mathrm{CaCl}_{2} / \mathrm{d} l \mathrm{CH}_{3} \mathrm{OH} \\
{[\eta] } & =3.86 \times 10^{-3} M^{0.506}, \\
& \text { in } 20-\mathrm{g} \mathrm{CaCl}_{2} / \mathrm{d} l \mathrm{CH}_{3} \mathrm{OH}
\end{aligned}
$$

The exponents of $M$ in $15-\mathrm{g} / \mathrm{d} l$ - and $20-\mathrm{g} / \mathrm{d} l-\mathrm{CaCl}_{2}$ solutions are 0.500 and 0.506 , respectively. This fact means that the former solution just satisfies the theta condition and the latter one is very close to the theta solution. The experimental results were plotted according to Fixman's equation $^{10}$ in Figure 4. From the intercept on the ordinate, we obtain $K_{\theta}$ in the equation $[\eta]=K_{\theta} M^{0.5}$ as $K_{\theta}=3.68 \times 10^{-3}$. Further, we estimate the ratio of the unperturbed meansquare end-to-end distance $\left\langle R_{0}^{2}\right\rangle$ to the molecular weight $M$, from the equation $K_{\theta}=\Phi_{0}\left[\left\langle R_{0}^{2}\right\rangle / M\right]^{3 / 2}$, by using the value $\Phi_{0}=2.5 \times 10^{21}$ :

$$
\left[\left\langle R_{0}^{2}\right\rangle / M\right]^{3 / 2}=1.14 \times 10^{-8} \mathrm{~cm} \mathrm{~mol}^{1 / 2} \mathrm{~g}^{-1 / 2}
$$

Finally we calculate the characteristic ratio, defined by $\left\langle R_{0}^{2}\right\rangle / n \bar{l}^{2}$, where $n$ is the number of chemical bonds in a Nylon chain and $\bar{l}$ is the average length of the bond, $\bar{l}=2.22 \mathrm{~A}$ :

$$
\left\langle R_{0}^{2}\right\rangle / n \bar{l}^{2}=9.41
$$

In Table VI, the characteristic ratios experimentally obtained for Nylon 66 by Saunders ${ }^{4}$ and theoretically calculated for Nylon 6, Nylon 66 , and a model polymer by Flory and Williams ${ }^{6}$, were compared with our result.

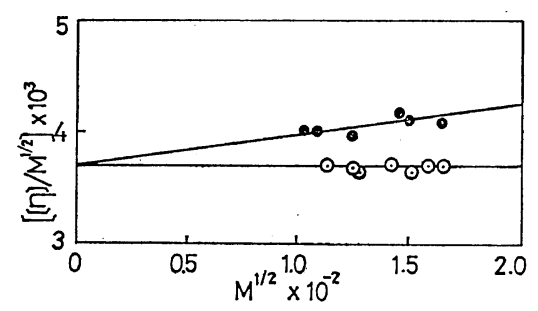

Figure 4. Fixman's plots for Nylon 6 in $\mathrm{CaCl}_{2}-$ methanol systems. Solvent composition: $(\bigcirc) 15-g$ $\mathrm{CaCl}_{2} / \mathrm{d} l$ methanol; (•) 20-g CaCl$/ 2 / \mathrm{d} l$ methanol. 
Dissolution and Chain Dimensions of Nylon 6 in Metal Halide-Alcohol Systems

Table VI. Comparison of characteristic ratios of Nylon

\begin{tabular}{llcccl}
\hline \multicolumn{1}{c}{ Author } & \multicolumn{1}{c}{ Polymer } & \multicolumn{1}{c}{$K_{\theta}$} & $\left\langle R_{0}^{2}\right\rangle / n \bar{l}^{2}$ & ${ }^{\circ} \mathrm{C}$ & \multicolumn{1}{c}{ Solvent } \\
\hline this work & Nylon 6 & $3.68 \times 10^{-3}$ & 9.41 & 35 & $\mathrm{CaCl}_{2}-\mathrm{CH}_{3} \mathrm{OH}$ \\
Saunders & Nylon 66 & $1.92 \times 10^{-3}$ & 6.10 & 25 & $2.3-M$ KCL/90-\% formic acid \\
Flory & Nylon 6 & & 6.08 & 25 & calculation \\
Flory & Nylon 66 & & 6.10 & 25 & calculation \\
Flory & Model polymer including & & 8.93 & 25 & calculation \\
& trans-C ${ }_{2}-\mathrm{CH}_{2}$ in place \\
& of CO-NH of Nylon 6. & & & & \\
\hline
\end{tabular}

Saunders ${ }^{4}$ reported that an aqueous solution of $90-\%$ formic acid including $2.3-\mathrm{mol} / l \mathrm{KCl}$ acts as a theta solvent for Nylon 66 at $25^{\circ} \mathrm{C}$, and obtained $K_{\theta}=1.92 \times 10^{-3}$. This value, using $\Phi_{0}=2.5 \times 10^{21}$, leads to $\left\langle R_{0}^{2}\right\rangle / n \bar{l}^{2}=6.10$, as shown in Table VI. Flory and Williams, ${ }^{6}$ on the other hand, have theoretically estimated the characteristic ratio as $\left\langle R_{0}^{2}\right\rangle / n \bar{l}^{2}=6.08$ by using the statistical weights $\sigma$ 's and $\omega$ 's for the three-bond and four-bond interactions, respectively. They assigned $\sigma=0.43, \sigma_{\alpha}=\sigma_{\beta}=\sigma_{r}=\sigma_{\delta}=1, \omega=0.034$, and $\omega_{\alpha}=\omega_{\beta}=\omega_{\gamma \delta}=\omega_{\delta}=0.10$, and derived $\left\langle R_{0}^{2}\right\rangle / n \bar{l}^{2}=6.08$ for Nylon 6. Saunders' experimental characteristic ratio coincides with Flory's theoretical one. Our experimental value is larger than Flory's value by more than $50 \%$, and also larger than the value 8.0 for polyethylene. Flory ${ }^{6}$ also calculated the characteristic ratio for a virtual polymer which replaces the $\mathrm{CO}-\mathrm{NH}$ of Nylon 66 by a trans $-\mathrm{CH}_{2}-\mathrm{CH}_{2}$; using $\sigma=0.43$ and $\omega=0.034$, he obtained $\left\langle R_{0}^{2}\right\rangle / n \bar{l}^{2}=8.93$. This value is rather close to our experimental value 9.41 .

The difference between our experimental value

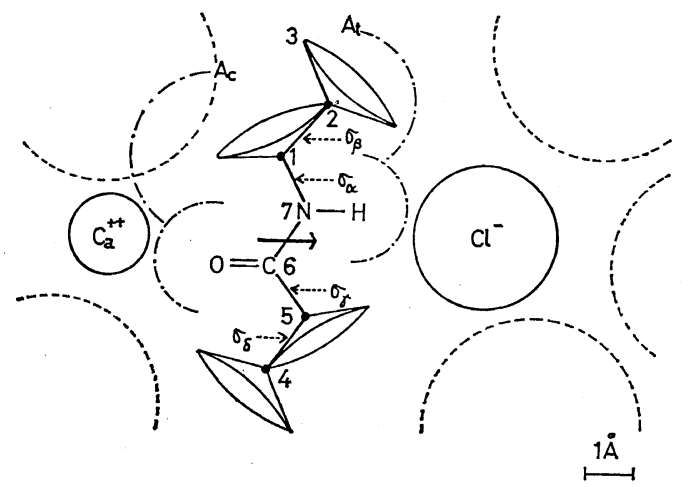

Figure 5. Dissolution of Nylon 6 in the $\mathrm{CaCl}_{2}-$ methanol system. and Flory's theoretical value for the $\left\langle R_{0}^{2}\right\rangle / n \bar{l}^{2}$ of Nylon 6 can be explained by taking into account the specific solvent effect for the unperturbed chain dimension in a complex solvent such as those used in the present study.

We propose a model, indicated in Figure 5, for Nylon 6 dissolved in a $\mathrm{CaCl}_{2}$-methanol mixture. In this figure, the symbols $\sigma$ 's are the same as Flory's ${ }^{6}$. The filled circle denotes the methylene unit, and the arrow designates the dipole moment (3.7 Debye ${ }^{11}$ ) of the amide group. Further, the broken circle (------) denotes the van der Waals' radius for methanol, assumed to be $2.5 \AA$, and circles $\mathrm{A}_{t}$ and $\mathrm{A}_{c}$ represent the van der Waals' radii $(2.0 \AA)$ for the methylene groups $\mathrm{C}_{(2)}$ which are located at the trans and cis conformations around the bond $\mathrm{N}_{(7)}-\mathrm{C}_{(1)}$. For $\mathrm{Ca}^{++}$and $\mathrm{Cl}^{-}$, circles were drawn with their ion radii.

To stabilize the large dipole moment of the amide group, the cation $\mathrm{Ca}^{++}$and the anion $\mathrm{Cl}^{-}$ may locate approximately on the amide plane in the direction of the dipole. Either the cation or the anion forms a complex with the methanol; since the former is smaller than the latter in its ion radius, the cation is more strongly solvated than the anion. For example, the electric displacement $e / r^{2}$ at $r=2 \AA$ from the center of a univalent ion is extremely large: $e / r^{2}=1.2 \times 10^{6}$ e.s. u. Thus, the nearest neighbor molecule may be strongly oriented toward the ion.

Flory and Williams ${ }^{6}$, in the calculation of the chain dimension, designated $\sigma$ the statistical weight factor of the gauche $(+)$ or gauche $(-)$ conformation normalized to a weight of unity for the trans conformation, and assigned $\sigma_{\alpha}=\sigma_{\beta}=\sigma_{\gamma}=1$ and $\sigma_{\delta}=0.5-1$ for the four methylene units adjoining the amide group, i.e., $C_{(1)}, C_{(2)}, C_{(5)}$ and $C_{(4)}$. For the other 


\section{A. Nakajima and K. TanaAmi}

methylene, $\mathrm{C}_{(3)}$, they assigned $\sigma=0.43$ on the basis of a calculation for polyethylene. In other words, with respect to the four methylene units adjoining to the amide group, Flory's model is very close to the free rotation model. Such a model leads, as a matter of course, to a rather small characteristic ratio.

To explain the numerical value of the characteristic ratio of Nylon 6 obtained in this work from measurements in the $\mathrm{CaCl}_{2}$-methanol system, the statistical weight factors used by Flory seem to be inadequate. The methylene units in our solvent system may have some interactions with the nearest neighbor methanol molecules solvated to the ions, and thus the amide group may be sandwiched with these solvated ions. Such interactions would reduce $\sigma_{\alpha}, \sigma_{\beta}, \sigma_{\gamma}$, and $\sigma_{\delta}$ from unity and make the characteristic ratio larger. Thus the numerical value, $\left\langle R_{0}^{2}\right\rangle / n \bar{l}^{2}=9.41$, obtained by us may be explained at least qualitatively. In our case, the solvent contributes to the short-range interference of the polymer chain. As mentioned above, the infrared spectra have indicated that the cation $\mathrm{Ca}^{++}$does not contact directly with the $\mathrm{C}=\mathrm{O}$ (at a distance equal to the sum of the ion radius of $\mathrm{Ca}^{++}$and the van der Waals' radius of $\mathrm{C}=\mathrm{O}$ ). This fact does not contradict our suggestion that some interactions exist between the methylene group and the methanol molecules.

Finally, we briefly mention the dissolution of Nylon 6 in the $\mathrm{CaCl}_{2}$-methanol system. For the amide portion, we have the following scheme:

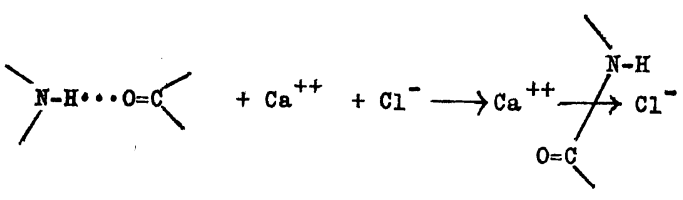

If the decrease of the free energy in this process overcomes the change of the free energy for all other portions, then Nylon 6 will be dissolved in this solvent system.

\section{REFERENCES}

1. O. E. Schupp, Jr., U.S. Patent 2359877 (1944).

2. R. A. Ford and H. S. B. Marshall, J. Polym. Sci., 22, 350 (1956).

3. T. Aoki, Lecture Meeting, "Technique for Producing Synthetic Leather," Japanese Soc. Mechanical Engineering, Tokyo, March 19, 1959.

4. P. R. Saunders, J. Polym. Sci., Part A-2, 2, 3765 (1964).

5. M. Kurata and W. H. Stockmayer, Fortschr. Hochpolymeren Forsch., 3, 196 (1963).

6. P. J. Flory and A. D. Williams, J. Polym. Sci., Part A-2, 5, 399 (1967).

7. M. Watanabe, Kobunshi Kagaku (Chem. High Polymers), 6, 216 (1949).

8. Goldschmidt, "Kagaku Binran", Chem. Soc. Japan Ed., 1958, p 1019.

9. H. Asai, M. Tsuboi, T. Shimanouchi, and S. Mizushima, J. Phys. Chem., 59, 78 (1955).

10. M. Fixman, J. Chem. Phys., 23, 1656 (1955).

11. R. M. Meighan and R. H. Cole, J. Phys. Chem., 68, 503 (1964). 